Available online on 15.10.2019 at http://ajprd.com
Open Access to Pharmaceutical and Medical Research

Open $\overbrace{\text { Access }}$

Research Article

\title{
Assessment of In-Vitro Antioxidant Potential of Ethyl Acetate Fraction of Hydroalcoholic Extract of Aerva Javanica Linn. Flowering Tops
}

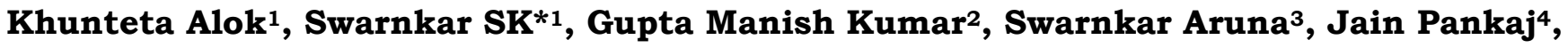 Paliwal Sarvesh4}

${ }^{1}$ LBS College of Pharmacy, Jaipur-302004, Rajasthan, India

${ }^{2}$ School of Pharmaceutical Sciences, Jaipur National University, Jaipur-302017, Rajasthan, India

${ }^{3}$ SMS Medical College, Jaipur, Rajasthan-302004, Rajasthan, India

${ }^{4}$ Department of Pharmacy, Banasthali Vidyapith, Banasthali, Newai, Rajasthan, India

\begin{abstract}
A B S T R A C T
Aerva javanica (Amaranthaceae) is a grey coloured woolly perennial tomentose shrub. Its traditional and folklore usage motivates further investigation on its pharmacognostic parameters and pharmacological potential. Therefore, in order to establish its antioxidant potential, DPPH, SOD and superoxide scavenging and total antioxidant capacity, were determined. Hydro-alcoholic extract $(\mathrm{CE})$ was prepared from flowering tops of $A$. javanica. In order to work further on activity guided fractions, ethyl acetate (AJEAF) fraction was prepared. For in-vitro evaluation, ascorbic acid was used as standard antioxidant compound. In DPPH assay $\mathrm{IC}_{50}$ was determined as $89.00 \mu \mathrm{g} / \mathrm{ml}$, as compared with standard ascorbic acid with $\mathrm{IC}_{50} 21.80 \mu \mathrm{g} / \mathrm{ml}$, with a concentration dependent scavenging of free radical. Superoxide scavenging potential in terms of SOD expressed as $\mathrm{IC}_{50}$, was determined as $61.904 \mu \mathrm{g} / \mathrm{ml}$ for AJEAF in contrast to $132.413 \mu \mathrm{g} / \mathrm{ml}$ for standard ascorbic acid. This was equivalent to $16.154 \mathrm{Eq}$ SOD units /mg (EAF) per mg of sample respectively against 7.552 Eq SOD units / $\mathrm{mg}$ of standard. Total antioxidant capacity was found to be $283.67 \mathrm{mg}$ Ascorbic acid Eq /g. Results indicated that fraction (AJEAF had significant antioxidant potential which expressed the prospective potential of fraction against metabolic disorders.
\end{abstract}

Keywords: Aerva, SOD, superoxide, antioxidant, ascorbic acid, FRAP

A R T I C L E I N F 0: Received 20 April 2019; $\quad$ Review Completed 18 July Oct. 2019; $\quad$ Accepted 10 Sept.. 2019; $\quad$ Available online 15 Oct. 2019

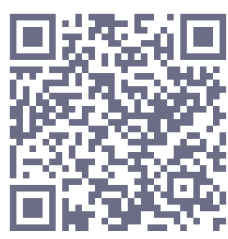

Cite this article as:

Khunteta A, Swarnkar SK*, Gupta MK, Swarnkar A, Jain P, Paliwal S, Assessment of In-Vitro Antioxidant Potential of Ethyl Acetate Fraction of Hydroalcoholic Extract of Aerva Javanica Linn. Flowering Tops, Asian Journal of Pharmaceutical Research and Development. 2019; 7(5):133-136, DOI: http://dx.doi.org/10.22270/aiprd.v7i5.520

*Address for Correspondence:

SK Swarnkar, Department of Pharmacognosy, LBS College of Pharmacy, Udai Marg, Tilak Nagar, Jaipur-302004, Rajasthan, India

\section{INTRODUCTION}

$\mathrm{F}$ olklore usage of herbs in various ailments motivates research of traditional drugs in modern system. Indigenous medical system is much more explored to develop drugs from plants. ${ }^{1}$ Traditional use of Aerva javanica flower tops in is the basis of present study. Chopra (1956) reported its traditional use as demulcent, diuretic, anthelmintic and also in headache. Swellings were reported to be removed by administration of plant decoction. ${ }^{2,3}$ Aerva javanica Linn. (Amaranthaceae) also known as 'Patharphori', is a grey colored woolly, perennial, suffruticose, hoary-tomentose, erect to scandent dioecious conspicuous under shrub, $0.6-1 \mathrm{~m}$ tall. ${ }^{4,5}$ The present study was undertaken to evaluate the extract and its fractions for their involvement in scavenging of oxidative radicals. In this order, their superoxide scavenging and total antioxidant capacity were evaluated. 


\section{MATERIALS AND METHODS}

\section{MATERIALS:}

Absolute ethanol, acetate buffer (pH 3.6) (SD finechem), ascorbic acid (Himedia), DMSO (Rankem), DPPH (2,2diphenyl-1-picryl-hydrazyl-hydrate) (Himedia), EDTA (SD finechem), Malondialdehyde (MDA) (Himedia), methanol, nitroblue tetrazolium (NBT) (Himedia), sodium hydroxide (Rankem), phosphate buffer pH 7.4 (Himedia), sulphuric acid (Rankem)

\section{METHODS:}

\section{Collection and Extraction}

Aerva javanica flowering tops were collected from forests of Jhalana in periphery of Jaipur, Rajasthan and authentication was done at "Department of Botany, University of Rajasthan, Jaipur" (Voucher specimen no. \#RUBL2116644) (Authentication certificate Ref. no.: Bot/2017/5424 dated 13/02/2017).

Hydro-alcoholic (50-50) extract was prepared from air dried plant materials using maceration method. Fractionation was carried out by first defatting and then by solvents of increasing polarity (dielectric constant). Solvents used for this purpose were petroleum ether, diethyl ether, ethyl acetate, benzene, acetone, and ethanol. Ethyl acetate (AJEAF) fraction was further used to assess antioxidant potential.

\section{Preparation of stock solutions:}

Stock solutions of extracts and standard- ascorbic acid were prepared in concentration of $1000 \mu \mathrm{g} / \mathrm{ml}$ in methanol. From the stock solutions, serial dilutions of the samples and standard were prepared to obtain different concentration viz. $2,4,8,16,32,64,128,256,512,1000 \mu \mathrm{g} / \mathrm{ml}$ were prepared in methanol and used for antioxidant studies.

\section{DPPH Radical Scavenging}

$1 \mathrm{ml}$ of methanolic extract of various concentrations was taken in test tube with $1 \mathrm{ml}$ of DPPH solution $0.1 \mathrm{mM}(0.39$ $\mathrm{mg}$ in $10 \mathrm{ml}$ methanol). Control was prepared with an equal amount of methanol and DPPH. Ascorbic acid was used as the standard to compare. All samples were incubated in dark for 20 minutes and absorbance was recorded at $517 \mathrm{~nm}$ in UV spectrophotometer. Experiment was performed in triplicate. ${ }^{6.8}$

\section{Superoxide Scavenging}

Different concentrations of extracts were prepared. Alkaline DMSO $(1 \mathrm{ml}$ DMSO containing $5 \mathrm{mM} \mathrm{NaOH}$ in $0.1 \mathrm{ml}$ water) and nitro blue tetrazolium (NBT) $20 \mathrm{mM} \mathrm{(50} \mathrm{mg} \mathrm{NBT}$ in $10 \mathrm{ml}$ phosphate buffer $\mathrm{pH}$ 7.4) solutions were prepared. $1.5 \mathrm{ml}$ of sample of different concentrations was taken and 2 $\mathrm{ml}$ alkaline DMSO was mixed and vortexed with it. To this mixture $0.6 \mathrm{ml}$ NBT reagent solution was added and vortexed. Final mixture was measured for absorbance at 560 nm under UV spectrophotometer. (9-11)

Scavenging of superoxide free radicals by extracts and fractions was calculated using following formula as \% scavenging:

$$
\% \text { Scavenging }=100-\left(\frac{\text { Abs.of control-Abs of sample }}{\text { Abs of control }}\right) x 100
$$

\section{Total Antioxidant}

$10 \mathrm{mg} / \mathrm{ml}$ stock solutions of extracts were prepared in water. $0.1 \mathrm{ml}$ of extract solution was mixed with $1 \mathrm{ml}$ of the reagent solution $(0.6 \mathrm{M}$ sulphuric acid, $28 \mathrm{mM}$ sodium phosphate and $4 \mathrm{mM}$ ammonium molybdate). Test tubes were covered from top and incubated at $95^{\circ} \mathrm{C}$ for $90 \mathrm{~min}$. After cooling to room temperature, the absorbance was measured at $695 \mathrm{~nm}$ in UV spectrophotometer (Shimadzu). Ascorbic acid was used as standard and calibration curve was prepared which was used to calculate total antioxidant activity in terms of number of equivalents of ascorbic acid per gram extract. ${ }^{6,8}$

\section{Statistical Analysis}

All results are expressed as mean \pm S.E.M. Linear regression analysis was used to calculate the $\mathrm{IC}_{50}$ values when required.

\section{RESULTS AND DISCUSSIONS}

\section{DPPH Radical Scavenging}

Table 1: Inhibition (\%) and inhibitory concentration (IC50) values of DPPH free radical by extracts

\begin{tabular}{|c|c|c|c|c|c|c|c|c|}
\hline \multirow{3}{*}{$\begin{array}{c}\text { Sample } \\
\text { type }\end{array}$} & \multicolumn{5}{|c|}{ Conc. $(\mu \mathrm{g} / \mathrm{ml})$} & \multirow[t]{3}{*}{ Linear equation } & \multirow{3}{*}{$\begin{array}{c}\text { Correlation } \\
\text { co-efficient } \\
\left(\mathbf{R}^{2}\right)\end{array}$} & \multirow{3}{*}{$\begin{array}{c}\mathrm{IC}_{50} \\
(\mu \mathrm{g} / \mathrm{ml})\end{array}$} \\
\hline & 20 & 40 & 60 & 80 & 100 & & & \\
\hline & \multicolumn{5}{|c|}{$\%$ Inhibition* } & & & \\
\hline AJEAF & $31.26 \pm 0.12$ & $35.23 \pm 0.13$ & $41.51 \pm 0.18$ & $48.77 \pm 0.11$ & $52.63 \pm 0.25$ & $y=0.281 x+24.99$ & 0.989 & 89.00 \\
\hline Asc. acid & $48.57 \pm 1.98$ & $57.76 \pm 1.81$ & $65.94 \pm 0.55$ & $72.53 \pm 0.55$ & $80.63 \pm 1.51$ & $y=0.394 x+41.41$ & 0.997 & 21.80 \\
\hline
\end{tabular}

*Inhibition \% represented as mean $\pm \mathrm{SD}$ of triplicate values. 


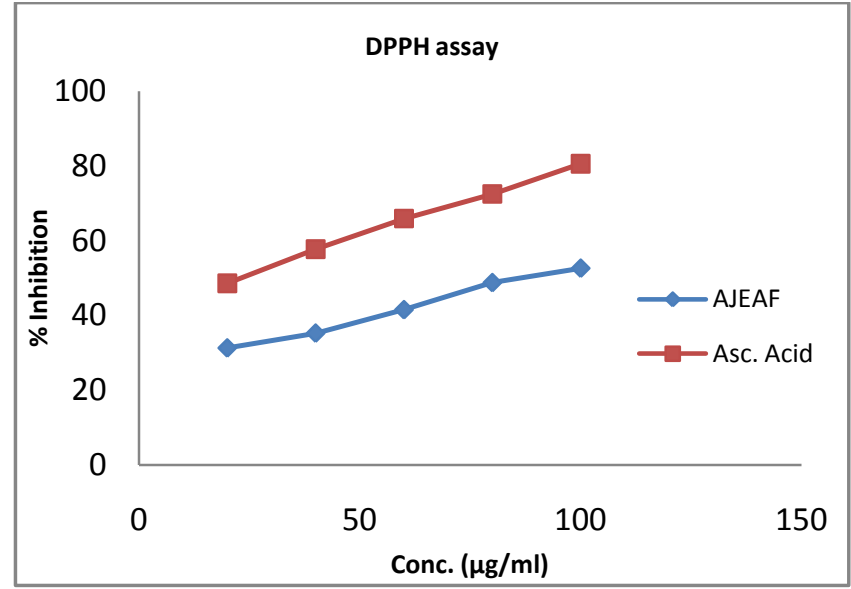

Figure 1: DPPH assay of various extracts and fractions

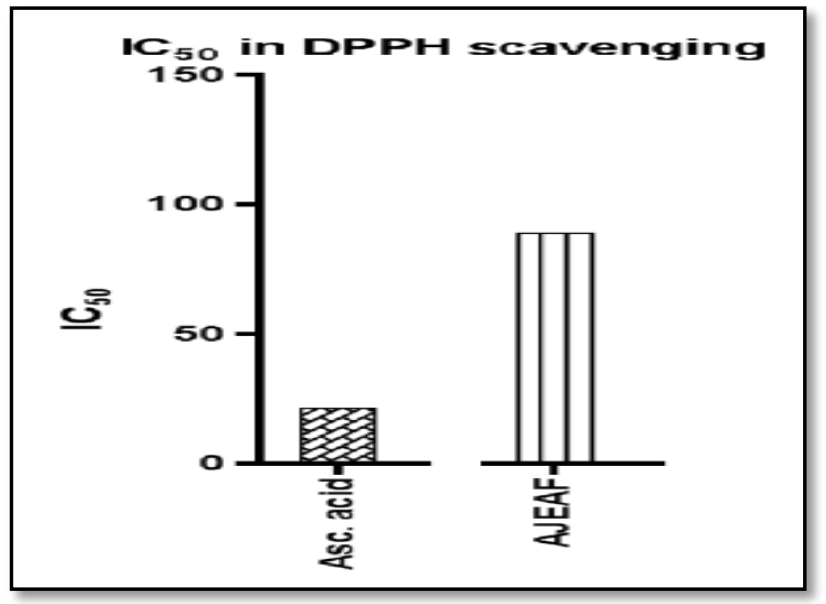

Figure 2: $\mathrm{IC}_{50}$ of AJEAF and ascorbic acid in DPPH scavenging

DPPH scavenging was determined as IC50 comparing with standard ascorbic acid. Ethyl acetate fraction (AJEAF) show 89 $\mu \mathrm{g} / \mathrm{ml}$ comparing to ascorbic acid at $21.80 \mu \mathrm{g} / \mathrm{ml}$. Fair DPPH radical scavenging capacity suggests its use as antioxidant scavenger.

\section{Superoxide Scavenging}

Table 2: Superoxide scavenging with SOD values for AJEAF and ascorbic acid at $560 \mathrm{~nm}$

\begin{tabular}{|c|c|c|c|c|}
\hline \multirow[t]{2}{*}{ Conc. $(\mu \mathrm{g} / \mathrm{ml})$} & \multicolumn{2}{|c|}{ Ascorbic acid } & \multicolumn{2}{|c|}{ AJEAF } \\
\hline & Absorbance & $\%$ inhibition & Absorbance & $\%$ inhibition \\
\hline 31.125 & 0.055 & 8.112 & 0.218 & 32.153 \\
\hline 62.500 & 0.131 & 19.322 & 0.334 & 49.263 \\
\hline 125.000 & 0.309 & 45.575 & 0.600 & 88.496 \\
\hline 150.000 & 0.412 & 60.767 & -- & -- \\
\hline 250.000 & 0.671 & 98.968 & - & -- \\
\hline 500.000 & -- & -- & -- & -- \\
\hline Linear Equation & \multicolumn{2}{|c|}{$\mathrm{y}=0.421 \mathrm{x}-5.746$} & \multicolumn{2}{|c|}{$y=0.604 x+12.61$} \\
\hline Correlation co-efficient $\left(\mathbf{R}^{2}\right)$ & \multicolumn{2}{|c|}{ ath $0.988 \theta^{2}$} & \multicolumn{2}{|c|}{0.998} \\
\hline $\mathrm{IC}_{50}(\mu \mathrm{g} / \mathrm{ml}) \equiv 1$ unit of SOD* & \multicolumn{2}{|c|}{132.413} & \multicolumn{2}{|c|}{61.904} \\
\hline Eq SOD units/mg ext or std. & \multicolumn{2}{|c|}{7.552} & \multicolumn{2}{|c|}{16.154} \\
\hline
\end{tabular}

Scavenging of superoxide free radicals by extracts and fractions was calculated using following formula as \% scavenging:

$$
\% \text { Scavenging }=100-\left(\frac{\text { Abs.of control-Abs of sample }}{\text { Abs of control }}\right) \times 100
$$

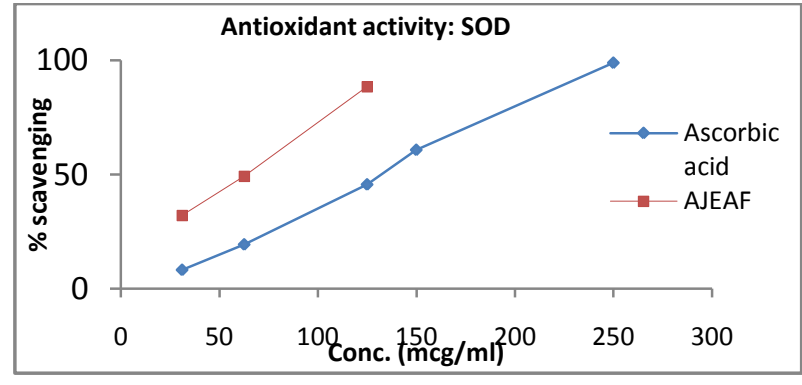

Figure 3: Superoxide scavenging activity as \% inhibition

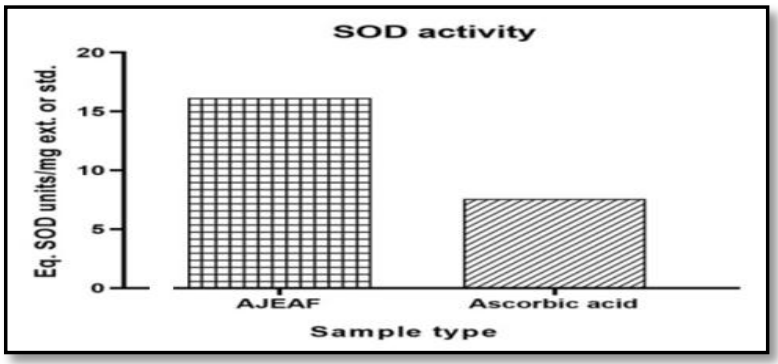

Figure 4: Superoxide scavenging activity as \% inhibition 
SOD activity (superoxide scavenging capacity) was found to be 16.15 equivalent SOD unit/mg of ethyl acetate fraction of Aerva javanica. The activity of AJEAF was found even better than standard ascorbic acid (7.55 eq. SOD unit/mg of extract) used. This suggests the very high concentrations of polyphenolics and in particular, flavonoids in the fraction and, was therefore of particular interest for further pharmacological investigation.

\section{Total Antioxidant}

Table 3: Total antioxidant- calibration curve data for standard ascorbic acid

\begin{tabular}{|l|c|c|c|c|c|}
\hline $\begin{array}{l}\text { Ascorbic acid } \\
\text { Conc. }(\boldsymbol{\mu g} / \mathbf{m l})\end{array}$ & $\mathbf{3 1 . 2 5}$ & $\mathbf{6 2 . 5}$ & $\mathbf{1 2 5}$ & $\mathbf{2 5 0 0}$ & $\mathbf{5 0 0}$ \\
\hline Mean Abs. & 0.045 & 0.178 & 0.274 & 0.479 & 0.892 \\
\hline SD & 0.010 & 0.015 & 0.019 & 0.018 & 0.019 \\
\hline Equation & $\mathrm{y}=0.001 \mathrm{x}+0.039$ \\
\hline $\mathbf{R}^{2}$ & 0.991 \\
\hline
\end{tabular}

Calibration curve: Total antioxidant capacity

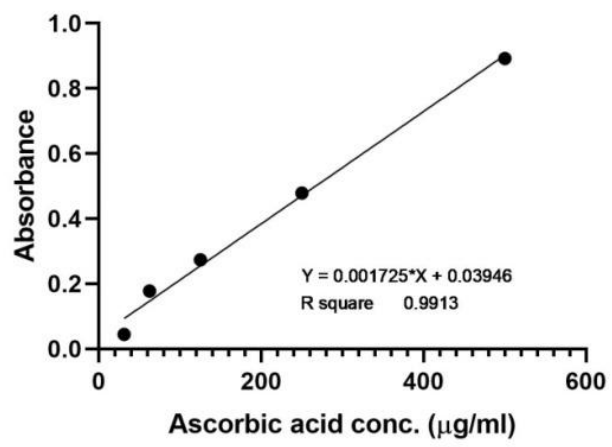

Figure 5: Total antioxidant- calibration curve for standard ascorbic acid

Total antioxidant capacity of ethyl acetate fraction (AJEAF) was calculated as $283.67 \mathrm{mg}$ Ascorbic acid Eq/g using the calibration curve of standard ascorbic acid. High value of total antioxidant capacity was due to the fact that the fraction have high concentrations of polyphenloics which are, by nature, powerful antioxidant.

\section{CONCLUSIONS}

From the results of present study, this can be concluded that extract in study possess powerful antioxidants which are more firmly distributed to ethyl acetate fraction. The possibility of counteracting oxidative stress by a pool of proper antioxidants plus an appropriate diet, mainly in patients whose blood antioxidant deficiencies can be easily rebalanced, may have real health benefit and represent a promising way of inhibiting the progression of disease.

\section{ACKNOWLEDGEMENT}

Authors are thankful to administration of Banasthali Vidyapith, Banasthali, Rajasthan and Dr. Rakesh Gupta, LBS College of Pharmacy, Jaipur, Rajasthan for providing adequate facilities and place to work.

\section{REFERENCES}

1. Nair S, Nair M, Nair D, Juliet S, Padinchareveetil S, Samraj S, et al. Wound Healing, Anti Inflammatory Activity and Toxicological Studies of Leea Asiatica (L.) Ridsdale. Int J Biol Pharm Res. 2014; 5(9):745-9.

2. Kirtikar K, Basu B. Indian Medicinal plants Plates 2018; 4:791.

3. Chopra R, Nayar S, Chopra I. Glossary of Indian Medicinal Plants. CSIR,(New Delhi, India). 1956; 186-7.

4. Movaliya V, Zaveri M. A review on the pashanbheda plant "Aerva javanica.” Int J Pharm Sci Rev Res. 2014; 25(2):268-75.

5. Soliman MA. Cytogenetical studies on Aerva javanica (Amaranthaceae). Flora Mediterr. 2006; (16):333-9.

6. Molyneux P. The use of the stable free radical diphenylpicryl- hydrazyl (DPPH) for estimating antioxidant activity. Songklanakarin J Sci Technol. 2004 ;26(2):211-9.

7. Schlesier K, Harwat M, Böhm V, Bitsch R. Assessment of antioxidant activity by using different in vitro methods. Free Radic Res. 2002;36(2):177-87.

8. Manda H, Rao BK, Yashwant, Kutty NG, Swarnkar A, Swarnkar SK. Antioxidant, Anti-Inflammatory and Antipyretic Activities of Ethyl Acetate Fraction of Ethanolic Extract of Schrebera swietenioides roxb. Root. Int J Toxicol Pharmacol Res. 2009; 1(1):7-11.

9. Laxane SN, Swarnkar SK, Setty MM. Antioxidant studies on the ethanolic extract of Zornia gibbosa. Pharmacologyonline. 2008; 1:319 30.

10. Govindarajan R, Vijayakumar M, Rawat AKS, Mehrotra S. Free radical scavenging potential of Picrorhiza kurrooa Royle ex Benth. Indian J Exp Biol, 2003 ; 41(8):875-9.

11. Swarnkar SK, Dwivedi D, Sharma R, Gupta D, Kaushik K, Gupta P. Assessment of superoxide scavenging and total antioxidant potential of hydroalcoholic extract of Aerva javanica Linn. flowering tops. Asian J Biochem Pharm Res,2019; (SI):22-6.

12. Prieto P, Pineda M, Aguilar M. Spectrophotometric quantitation of antioxidant capacity through the formation of a phosphomolybdenum complex: specific application to the determination of vitamin E. Anal Biochem. 1999;269(2):337-41.

13. Shirwaikar A, Rajendran K, Kumar CD. In vitro antioxidant studies of Annona squamosa Linn. Leaves. Indian J Exp Biol. 2004;42(8):803-7. 